\title{
Lo que le queda al traductor es hacer traducción honesta: apuntes sobre tres traducciones al español de "La capra" de Umberto Saba
}

\author{
What Remains for Translators Is to Do an Honest Translation: \\ A Commentary on Three Translations \\ of Umberto Saba's "La capra"
}

\author{
Montserrat Mira Mosso \\ Facultad de Filosofía y Letras \\ Universidad Nacional Autónoma de México | México \\ Contacto: montserratmira@filos.unam.mx
}

\section{Resumen}

En ocasiones, al momento de determinar si una traducción ha sido o no afortunada, los criterios de valoración se limitan a la legibilidad o fluidez, o bien, a su carácter extranjerizante o domesticante. Sin embargo, siguiendo de cerca las ideas propuestas por Jiří Levý en su obra The Art of Translation (2011) respecto a la traducción literaria, en este trabajo me ha parecido más fructífero tomar como punto de partida no sólo las características evidentes del texto fuente, sino, sobre todo, la poética del propio autor. En este caso, retomaré la figura del poeta italiano Umberto Saba (Trieste 1883 - Gorizia 1957) y algunas de sus principales consideraciones en torno a la poesía y el oficio de poeta. Me centraré en especial en el ensayo "Quello che resta da fare ai poeti", en el que Saba afirma categórico que la única búsqueda que deberían seguir los poetas es escribir poesía honesta. Tomando como base justamente la poética sabiana de la "poesía honesta", en este trabajo trataré de establecer si los principios poéticos expuestos por el autor se pueden reconocer todavía tras el proceso de traducción. Con este propósito recupero el poema "La capra", uno de los poemas más emblemáticos de poeta triestino, y analizo las versiones al español de los traductores Antonio Colinas (1977), Ana María del Re (1989) y Guillermo Fernández (2006).

Palabras clave: crítica de traducción, Jiří Levý, traducción de poesía, Umberto Saba, Saba y la poesía honesta

\begin{abstract}
At times, when one assesses whether a translation is apt or not so much, the evaluation criteria are limited to its legibility or fluency, or else, to its foreignizing or domesticating nature. Nevertheless, following Jiř́ Levýs The Art of Translation and his ideas about literary translation, in this work I consider it more fruitful not only to establish the evident characteristics of the text as a starting point, but, above all, the poetics of its writer. For this research I will focus on the Italian poet Umberto Saba (Trieste 1883 - Gorizia 1957) and his most important ideas about poetry and a poet's craft, especially on his essay "Quello che resta da fare ai poeti," in which the author asserts that, for poets, the only thing that remains is to write honest poetry. Using Saba's poetics of "honest poetry" as a starting point, I will try to determine if some of the poetic principles exposed by Saba can be recognized in his poems even after a translation process. For my analysis I will use "La capra", one of the Italian poet's most emblematic works, to later present and compare the Spanish translations by Antonio Colinas (1977), Ana María del Re (1989) and Guillermo Fernández (2006).
\end{abstract}

Keywords: translation criticism, Jiří Levý, poetry translation, Umberto Saba, Saba's honest poetry 


\section{Introducción}

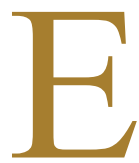

$\mathrm{n}$ este trabajo me propongo hacer una revisión de tres traducciones al español del poema "La capra", del poeta italiano Umberto Saba (Trieste 1883 - Gorizia 1957), a la luz de las ideas que el propio autor concibió acerca de la poesía. Mi interés por este autor responde, por un lado, al hecho de que Saba, cuya trascendencia es hoy unánimemente reconocida por la crítica, fue considerado, en algún momento, más bien una figura periférica en el panorama de la literatura italiana del siglo xx, respecto a poetas como Giuseppe Ungaretti o Eugenio Montale. Por otro lado, me parece interesante recuperar la concepción sabiana sobre poesía y tratar de analizar en qué medida ésta se preserva y es reconocible en las versiones de los poemas en español.

Con este fin será útil recordar algunas consideraciones expuestas por Jiř́i Levý (2011), en su obra The Art of Translation, a propósito del proceso de traducción: la lectura atenta y profunda requerida al traductor, la aprehensión e interpretación de la obra fuente, así como su posterior re-estilización. Como señala el crítico checo, un factor que puede resultar vital para el traductor es su conocimiento sobre las circunstancias (históricas, espacio-temporales, ideológicas, etcétera) que enmarcaron la producción de la obra por traducir - es decir, su conocimiento de todo aquello que, además del texto en sí mismo, pueda brindarle luces sobre la esencia del texto.

Precisamente, para tratar de entender mejor esta esencia de la obra de Saba, y más específicamente del poema que me ocupa, será necesario referir brevemente el panorama en el que se inscribe la obra de este poeta "periférico"; sobre todo, será útil recordar las reflexiones del propio autor en torno a su oficio. Para ello me remitiré a dos textos fundamentales de Umberto Saba: el ensayo "Quello che resta da fare ai poeti" (1911), en el que el escritor expone su principio de "poesía honesta" y deja claro cuál es su búsqueda a través de la poesía, y algunos pasajes de la Storia e cronistoria del Canzoniere (1948), una detallada revisión que, en el papel de crítico, lleva a cabo el propio Saba sobre su producción poética.

Una vez delineada la poética sabiana, será posible analizar las tres versiones del poema al español. No parece ser hoy una revelación decir que las diversas traducciones de un mismo texto hacia una misma lengua meta (incluso si ésta es bastante cercana a la lengua fuente, como en el caso del español y el italiano) presentarán siempre diferencias. Sin embargo, más allá de los meros juicios de valor, resulta interesante identificar dichas diferencias, reflexionar en qué consisten, de dónde surgen y en qué medida fueron determinantes en el proceso y resultado de la traducción.

Para este estudio servirán como base las versiones de Antonio Colinas (1977), Ana María del Re (Saba, 1989) y Guillermo Fernández (2006). Con esto no pretendo establecer la mayor o menor pertinencia de una de las versiones sobre las otras, sino más 
bien tratar de rastrear en ellas en qué medida la esencia de la poética sabiana se percibe tras el proceso de traducción.

\section{Umberto Saba y la poética de la honestidad}

Escribía Elsa Morante (1987) hacia 1957, a propósito de la muerte de Umberto Saba:

Se agli uomini fosse dato (ciò che di rado è dato) di comprendere il valore e la misura dei loro contemporanei, oggi, per la scomparsa di Umberto Saba, tutta la nazione italiana dovrebbe essere in lutto [...]. Difatti a Umberto Saba si addisce quel raro aggettivo che oggi non si ha mai il coraggio di usare per i poeti, ma che in compenso si usa troppo spesso (e troppo a sproposito) per dittatori sanguinari, attori mediocri, e simili: l'aggettivo "grande". Umberto Saba è un grande poeta, e vivrà fra i più grandi poeti della nostra storia letteraria. ${ }^{1}$ (37)

La apreciación de Morante sobre el poeta triestino parece haber sido, además de adelantada, acertada; hoy Saba es considerado uno de los grandes poetas italianos del siglo Xx. Es innegable reconocer en las palabras de Morante un cierto reproche a la crítica de aquel tiempo, "con le loro intelligenze distratte e riduttive"2 (Morante, 1987: 38), por su poca atención a la obra sabiana. Precisamente este contraste de apreciación entre la crítica de aquella época y la crítica más reciente será un buen punto de partida para comprender mejor la poesía de Saba, situándola en el panorama italiano de aquellos años para, posteriormente, revisar la pertinencia de las diversas traducciones del poema que me ocupará.

Podríamos empezar por preguntarnos qué rasgos particulares presentaba la poesía de Saba para que resultara un tanto ajena al clima intelectual y artístico general de su época y, por tanto, para hacer de su autor, en algún momento, un poeta más bien periférico. Una primera pista nos la brinda el mismo Saba en su Storia e cronistoria del Canzoniere, cuando se pregunta sobre las posibles causas de la incomprensión y tardío reconocimiento de su obra: "Perché si cercò sempre, o quasi sempre, non di negare quella poesia [...] ma di diminuirne la vastità e la portata?”3 (Saba, 1963: 21).

1 [Si a los hombres les fuera dado (lo que rara vez les es dado) comprender el valor y la medida de sus contemporáneos, hoy, por la muerte de Umberto Saba, toda la nación italiana debería estar de luto [...]. En efecto, a Umberto Saba se adhiere ese raro adjetivo que no se tiene nunca el valor de usar para los poetas, pero que en cambio se usa con demasiada frecuencia (y demasiado arbitrariamente) para dictadores sanguinarios, actores mediocres, y otros similares: el adjetivo "grande". Umberto Saba es un gran poeta, y vivirá entre los más grandes poetas de nuestra historia literaria.] (Las traducciones en nota al pie son mías.)

2 [con sus inteligencias distraídas y reductivas]

3 [¿Por qué se trató siempre, o casi siempre, sino de negar aquella poesía [...] sí de disminuir su vastedad y su alcance?] 
Saba atribuye dicha incomprensión principalmente a dos causas o fatalità, como él las denomina: una interna, "nella natura cioè del poeta", ${ }^{4}$ y una externa, "nell'ambiente dal quale egli prese le mosse e nel quale agi"'5 (Saba, 1963: 22). El poeta se refiere, por un lado, a algunas circunstancias cruciales de su vida que habrían de determinar su formación literaria y su particular concepción sobre la poesía y el oficio de poeta; por otro lado, alude a la lejanía, no sólo espacial, de Trieste (su ciudad natal) respecto a otras ciudades con una antigua tradición literaria:

Saba è nato a Trieste, nel 1883 [...] sua madre [...] era ebrea; suo padre che sparì subito dal cerchio della famiglia [...] "ariano". In questi scarsi dati di stato civile vi sono già [...] molti elementi isolanti. Nascita in una città di traffici e non di vecchia cultura, varia di razze e di costumi [...] Saba fu insomma, malgrado la sua italianità formale [...] e la sua universalità umana, un "periferico" [...] Le origini triestine di Saba hanno avuto anche come conseguenza, di farne, almeno agli inizi, un arretrato. ${ }^{6}$ (Saba, 1963: 23)

Quienes se han adentrado en la obra sabiana parecen coincidir con el autor respecto a la trascendencia que aquellos hechos tendrían en su obra. Su nacimiento en una "famiglia disunita", el drama interno por la ausencia paterna (de allí quizá su decisión de no usar el apellido paterno Poli y adoptar, en cambio, Saba, palabra de origen hebreo que significa "pan"), ${ }^{7}$ su formación literaria, más bien de autodidacta, y el fuerte arraigo que sentía hacia su ciudad natal, son todas experiencias que determinarían la naturaleza del poeta y su poesía. Sin embargo, es posible señalar aquí un punto de diferencia respecto a la opinión de Saba pues, si bien es cierto, como asegura el poeta, que estos "elementi isolanti" fueron quizá la principal causa de su lugar periférico, mirando en retrospectiva podríamos decir que quizá por esos elementos su poesía se distinguió de modas literarias restringidas a un tiempo determinado y le valió ser considerado actualmente un gran poeta.

Saba descubre su vocación poética muy pronto. Guiado por su propio instinto, cuando todavía "nessuno aveva parlato a lui di buoni o di cattivi autori"» (Saba, 1963: 24), se dedica al estudio de los clásicos: reconocerá más tarde la influencia de Dante, Petrarca,

4 [es decir, en la naturaleza del poeta]

5 [en el ambiente del que partió y en el que trabajó]

6 [Saba nació en Trieste, en 1883 [...] su madre [...] era judía; su padre que desapareció inmediatamente del círculo de la familia [...] "ario". En estos pocos datos de estado civil hay ya [...] muchos elementos aislantes. Nacimiento en una ciudad de tráfico comercial y no de vieja cultura, diversa en cuanto a razas y costumbres [...] En fin, Saba fue, a pesar de su italianidad formal [...] y su universalidad humana, un "periférico" [...] Los orígenes triestinos de Saba tuvieron también como consecuencia, situarlo, al menos al inicio, un paso atrás.]

7 Sobre el apellido Saba y su significado existe otra interpretación que lo atribuye al apellido Sabaz de la mujer encargada de la crianza del poeta durante su primera infancia.

8 [nadie le había hablado de buenos o de malos autores] 
Parini y Leopardi. Sobre todo este último significaría un importante hallazgo para el joven Saba quien, sintiéndose cercano al autor del "Canto notturno di un pastore errante dell'Asia", tendría la impresión "non già di leggerlo, ma di rileggerlo"9 (Saba, 1963: 41). De ellos aprenderá las formas, evidentes en sus primeras composiciones y constantes, en general, en su producción posterior. De ahí que se hablara de "conservadurismo sabiano", reprochándosele al autor su poca innovación en términos formales. Por su parte, Saba, como se verá más adelante, no se mostró nunca demasiado interesado por la búsqueda de lo "nuevo", ni siquiera cuando alrededor todo apuntó precisamente a lo novedoso, a la ruptura con la tradición (son los años fuertes del Futurismo y otras vanguardias). ${ }^{10}$

Como decía antes, no es sencillo adscribir la obra sabiana a la de sus contemporáneos o a una escuela de poesía determinada. De hecho, ya respecto a la generación de poetas inmediatamente anterior, el mismo Saba guardaba ciertas reservas, asegurando que ésta había dejado en él acaso una huella superficial (Saba, 1963: 41). Folco Portinari, al referirse a las primeras obras del poeta triestino, hace notar la poca sintonía entre el ambiente cultural que se respiraba en la Italia de aquellos años y la naturaleza de la poesía sabiana:

È facile [...] ripensare la vita letteraria di quegli anni, un principio di secolo con nomi noti e nuovi, che basta pronunciarli ormai per evocare un clima: D'Annunzio scrive le Laudi e Pascoli i Canti di Castelvecchio, il patriarca Carducci ha datato l'ultima delle Rime e ritmi nel 1895, Corazzini scrive le Dolcezze e Gozzano La via del rifugio. Le date sono quelle, eppure sfugge Saba, in definitiva, a quella compagnia. ${ }^{11}$ (Portinari, 1957: 15)

Es decir que Saba, a pesar de la lección aprendida de los clásicos e incluso a pesar de los rasgos que llegó a compartir con algunos contemporáneos, pronto desarrolló un estilo propio. El poeta centrará su atención en la vida y los ambientes cotidianos, en los recuerdos de infancia y juventud ("autobiografismo sabiano"), en las cosas minúsculas que tienden al mismo tiempo a lo universal; preferirá un lenguaje auténtico, no retórico ni preciosista pues, como él mismo asegura, nunca tuvo miedo de las palabras (Saba, 1963: 23-24). Más que cualquier estudio crítico, sería vital, para comprender a un autor, ir directamente a sus textos. Por esta razón, resultará revelador revisar la declaración poética del propio Saba: "Quello che resta da fare ai poeti”.

\footnotetext{
9 [no ya de leerlo, sino de releerlo]

10 Saba escribirá "Quello che resta da fare ai poeti”, su declaración poética, en 1911, apenas unos años después de la aparición del Manifeste du futurisme de F. T. Marinetti (1909).

11 [Es fácil [...] volver a pensar la vida literaria de aquellos años, un inicio de siglo con nombres famosos y nuevos, que basta pronunciarlos para evocar ya un clima: D’Annunzio escribe las Laudi y Pascoli los Canti di Castelvecchio, el patriarca Carducci fechó la última de las Rimas y ritmos en 1895, Corazzini escribe las Dolcezze y Gozzano La via del rifugio. Las fechas son éstas, y sin embargo escapa Saba, definitivamente, a esa compañía.]
} 
Hacia 1911, Umberto Saba escribe su "manifiesto" y, como era natural — dice Portinari (1957) - lo envía a la revista La Voce, punto de referencia cultural de la época. La revista devolverá el artículo al remitente. En efecto, el texto permanecerá inédito hasta 1959. En opinión de Portinari (1957), considerando las circunstancias de la época, no debería sorprender aquel rechazo del texto sabiano, en el que el autor no limitaba su posicionamiento a un plano meramente estético, sino también moral y humano.

Inicia Saba categórico "Ai poeti resta da fare la poesia onesta". ${ }^{12}$ Para él, en la literatura y específicamente en la poesía conviven dos cualidades opuestas: la honestidad y la deshonestidad literaria, con las que identifica respectivamente a Alessandro Manzoni y a Gabriele D'Annunzio. Del primero reconoce "la costante e rara cura di non dire una parola che non corrisponda perfettamente alla sua visione. Il piú sobrio dei poeti italiani $[. .$.$] per non travisare il propio io e non ingannare con false apparenze quello dei$ lettori, resta se mai al di qua dell'ispirazione"13 (Saba, 2001: 675). Del segundo, en cambio, reprueba ese "troppo artificio" 14 que, dice Saba, no es sólo formal sino también sustancial: “[D'Annunzio] si esagera o addiritura si finge passioni e ammirazioni che non sono mai state nel suo temperamento [...] al solo e ben meschino scopo di ottenere una strofa piú appariscente, un verso più clamoroso"15 (Saba, 2001: 675).

En la visión del triestino, la mayor deshonestidad que puede cometer un poeta es forzar la poesía y hacerla artificiosa con miras a obtener un mayor reconocimiento. Saba ve en esta postura "intenzioni bottegaie" 16 de quien considera la creación de versos igual a abrir un negocio. Así, el poeta aclara lo que significa para él la honestidad literaria: "è prima un non sforzare mai l'ispirazione, poi non tentare, per meschini motivi di ambizione e di successo, di farla parere più vasta e appariscente di quanto per avventura essa sia"17 (Saba, 2001: 676). A partir de estas breves líneas se puede vislumbrar qué significaba para Saba la poesía: ésta iba más allá de la experimentación lingüística o el efecto estético. Como asegura Folco Portinari (1957: 60), siguiendo al propio Saba, la poesía respondía a una búsqueda profunda por parte del poeta; nada de metafísico en ella, simplemente una búsqueda de sí mismo.

12 [A los poetas les queda escribir poesía honesta]

13 [el constante y raro cuidado de no decir una palabra que no corresponda perfectamente a su visión. El más sobrio de los poetas italianos [...] para no falsear su propio yo y no engañar con falsas apariencias el del lector, se detiene, si acaso antes de la inspiración.]

14 [demasiado artificio]

15 [D'Annunzio exagera o incluso finge pasiones y admiraciones que no han estado nunca en su temperamento [...] con el único y bien mezquino objetivo de obtener una estrofa más vistosa, un verso más clamoroso]

16 [intenciones mezquinas]

17 [es primero no forzar nunca la inspiración, luego no tratar de hacerla parecer, por mezquinos motivos de ambición y éxito, más vasta y vistosa de lo que por ventura ésta es] 
Quizá fue también su particular concepción de la poesía la que alejaba a Saba de las corrientes poéticas más en boga. Para nuestro autor lo "nuevo" tenía poco que ver con lo meramente novedoso:

Ecco la parola que se fa trasalire gli artisti fa tremare i poeti, perché in nessun arte le inconscie reminiscenze sono piú frequenti che in poesia, dove vengon favorite dalla natura stessa e dall'inevitabile virtù del suono che le imprime indelebilmente nella memoria. Di una poesia non resta solo, come di una prosa, lo spirito che l'animava, ma anche la materia in cui s'è incarnato. ${ }^{18}$ (Saba, 2001: 676)

Y se cuestiona Saba sobre el miedo dañino de ciertos poetas a "repetirse"; no entiende la excesiva preocupación por la originalidad: el poeta honesto, no puede más que ser original. Más que en la búsqueda de la originalidad per se, el punto nodal estaría, según Saba, en el motivo que desencadena dicha búsqueda: "Benché essere originali e ritrovar se stessi siano termini equivalenti, chi non riconosce in pratica che il primo è l'effetto e il secondo la causa, e parte non dal bisogno di riconoscersi ma da uno sfrenato desiderio dell'originalità [...] non riuscirà mai a trovare la sua vera natura"19 (Saba, 2001: 676-677). Así pues, el poeta honesto no se cuidará demasiado de las repeticiones, o diríamos tentativas, a las que lo empuja su necesidad expresiva.

\section{Tres versiones al español de "La capra"}

Para el traductor la poesía representa, quizá más que cualquier otro género, un reto particular. La dificultad puede nacer de ciertas cualidades inherentes a la poesía: la estrecha relación entre forma y contenido, el sonido y la musicalidad ligados a cuestiones métricas y de ritmo, la polisemia y la densidad de significado sintetizado en pocas palabras que brinda al lector más de una posibilidad de interpretación. De modo que si el propio poeta, como señalaba el mismo Saba, en el ejercicio creativo se enfrenta a este rasgo de la poesía, el desafío para el traductor resultaría doblemente complejo: no sólo debe afrontar la naturaleza propia de la poesía, sino que debe trasponerla a otra lengua, a otro contexto.

${ }^{18}$ [He aquí la palabra que si estremece a los artistas hace temblar a los poetas, porque en ningún arte las reminiscencias inconscientes son más frecuentes que en la poesía, donde éstas son favorecidas por la naturaleza misma de la poesía y por la inevitable virtud del sonido, que las graba de manera indeleble en la memoria. De una poesía no queda solamente, como de la prosa, el espíritu que la animaba, sino también la materia en la que se encarnó.]

${ }^{19}$ [Si bien ser original y encontrarse a sí mismo son términos equivalentes, quien no reconoce en práctica que el primero es el efecto y el segundo, la causa, y parte no de la necesidad de reconocerse sino de un desenfrenado deseo de originalidad [...] nunca podrá encontrar su verdadera naturaleza.] 
Teóricos como Jiři Levý se han detenido a reflexionar sobre todo lo que implica el proceso traductivo. Levý (2011), en su obra The Art of Translation, señala, en primer lugar, la importancia de la lectura atenta por parte del traductor. Ésta implica no sólo una comprensión e interpretación del texto, sino también una inmersión que permita vislumbrar qué hay detrás de él — es decir, conocer (o incluso ser capaz de imaginar) aquellos elementos que enmarcaron el nacimiento de la obra fuente y pudieron delinear su naturaleza (el contexto socio-histórico, la poética del autor, la tradición literaria en la que se inscribe, etcétera) - . El traductor debe valerse de todo aquello que le permita aprehender el tono del texto fuente (Levý, 2011). El caso de Saba no es la excepción: tener en mente sus consideraciones sobre la poesía y el oficio de poeta, así como las circunstancias en las que su obra se circunscribe, puede dar luces al traductor precisamente sobre el tono indicado por Levý.

No es banal la insistencia sobre el tono de la obra, en especial si consideramos que el contexto de la Italia de la primera mitad del siglo xx en el que escribió el poeta dista mucho del entorno de un lector hispanohablante en la actualidad. De ahí la importancia de que el traductor logre captar el tono que habrá de plasmar en el texto meta. En este punto del proceso de traducción hay un factor que podría pasar inadvertido pero que Levý recuerda: al igual que la obra, también el traductor está inserto en un contexto específico que en gran medida puede influir su labor.

En el caso de los traductores que me ocupan, será necesario tener presente esta consideración, pues los contextos en los que nacen las tres versiones al español son notoriamente distintos. Una primera diferencia serían las distancias espacio-temporales que las separan: la traducción de Antonio Colinas aparece en España bajo el sello Editora Nacional en 1977; por otro lado, Ana María del Re publica su versión en la editorial Monte Ávila en Venezuela en 1989; y finalmente, la traducción de Guillermo Fernández es publicada por la Universidad Nacional Autónoma de México en 2006. Cabe señalar además que en el caso de Colinas y Fernández se trata de antologías que incluyen varios poetas italianos del siglo xx; en el caso de Ana María del Re, en cambio, se trata de una obra dedicada exclusivamente al poeta triestino. Una diferencia más se puede observar en los paratextos: sólo Colinas y Del Re hacen la presentación de las respectivas obras, mientras que, en el caso de Fernández, el prólogo corre a cargo de Stefano Strazzabosco. Ninguna de las obras hace referencia a las estrategias y decisiones de traducción, ni siquiera en el caso de la recopilación sabiana de Ana María del Re.

Tras indicar estos pocos ejemplos de divergencias entre las tres obras, concernientes a los traductores, el contexto y los paratextos, no es difícil entender que exista variación en las traducciones. Teniendo en mente la poética de la "poesía honesta", así como las consideraciones sobre la traducción de poesía y los distintos traductores, será ya posible adelantar algunas hipótesis sobre las tres versiones. 
Perteneciente a la recopilación Casa e campagna (1909-1910), "La capra" es uno de los poemas más famosos de Saba. En él es posible encontrar los rasgos más distintivos de su poética: las formas métricas clásicas, el uso del encabalgamiento, el carácter prosístico caracterizado por un lenguaje llano. Al respecto apunta Gambarota (2005) que:

Saba strives to make up favolette, fairy tales, and light songs, written in a simple, apparently artless language. By privileging generic nouns for surrounding things and living beings and by naming only what belongs to a basic creatural experience (birth, love, pain, death), Saba draws from a language well that is common to all human beings as a species. He himself liked to qualify his poetry with the expression raso terra ("close to the ground"). (150)

Por otro lado, el poema presenta uno de los temas predilectos del autor: la identificación del hombre con los animales. En Saba, esta identificación respondía a su rechazo de la supuesta superioridad del hombre respecto a los animales. Como explica Gambarota (2005), el poeta se rehusaba a mirar el mundo "desde arriba" y, más bien, aspiraba a una comunión con la naturaleza y sus criaturas.

En el poema "La capra" vemos reflejada esta concepción sabiana:

Ho parlato a una capra.

Era sola sul prato, era legata.

Sazia d'erba, bagnata

dalla pioggia, balava.

Quell'uguale belato era fraterno

al mio dolore. Ed io risposi, prima

per celia, poi perché il dolore è eterno,

ha una voce e non varia.

Questa voce sentiva

gemere in una capra solitaria.

In una capra dal viso semita

sentivo querelarsi ogni altro male,

ogni altra vita. (Saba, 2014: 68)

Saba nos brinda en este poema una de sus imágenes más emblemáticas: la famosa cabra de rostro semita. Por una parte, la cabra es el símbolo por antonomasia de la vulnerabilidad y sacrificio; el adjetivo semita, por la otra, (intensificado por la imagen de 
la lluvia que moja al solitario animal) parece querer subrayar esta condición. El poema es, como escribiera Giorgio Bàrberi Squarotti, "la perfetta trasfigurazione di un episodio georgico in un simbolo della condizione universale di dolore immanente negli uomini come nella natura"20 (citado en Portinari, 1957: 51).

En estos trece versos (alternados entre heptasílabos y endecasílabos), de rima asonante, se reconoce ese carácter narrativo que se le ha atribuido a la poesía de Saba: el léxico es simple (salvo algunos cultismos como celia y querelarsi), las descripciones son pausadas por efecto de la yuxtaposición ("Era sola sul prato, era legata. / Sazia d'erba, bagnata / dalla pioggia, balava") y las ideas de mayor importancia se ubican en unidades de significado acentuadas por los encabalgamientos y las repeticiones (ha una voce e non varia. / Questa voce sentiva / gemere in una capra solitaria. / In una capra dal viso semita).

Analicemos las tres versiones en español estrofa por estrofa, iniciando por la primera (Tabla 1$):^{21}$

\section{Tabla 1}

Primera estrofa de "La cabra"

\begin{tabular}{lll}
\hline $\begin{array}{l}\text { Traducción } \\
\text { de Antonio Colinas }\end{array}$ & $\begin{array}{l}\text { Traducción } \\
\text { de Ana María del Re }\end{array}$ & $\begin{array}{l}\text { Traducción } \\
\text { de Guillermo Fernández }\end{array}$ \\
\hline $\begin{array}{l}\text { He hablado a una cabra. } \\
\text { Sola estaba en el prado, y atada. }\end{array}$ & $\begin{array}{l}\text { He hablado a una cabra. } \\
\text { Estaba sola en el prado, atada. }\end{array}$ & $\begin{array}{l}\text { Le hablé a una cabra. } \\
\text { Estaba sola y atada en el prado. } \\
\text { Saciada de hierba, mojada }\end{array}$ \\
$\begin{array}{l}\text { por la lluvia, balaba } \\
\text { por la lluvia, balaba. }\end{array}$ & $\begin{array}{l}\text { Ahíta de hierba, empapada } \\
\text { por la lluvia, balaba. }\end{array}$ \\
\hline
\end{tabular}

Fuentes: Colinas (1977: 89), Saba (1989: 72) y Fernández (2006, 104)

En los tres casos, los traductores logran mantener el metro en este fragmento (salvo en el tercer verso); sin embargo, sólo Colinas y Del Re conservan la rima asonante. Ya en el primer verso contrasta, en la versión de Fernández, la elección del pretérito simple, así como la inclusión del clítico "le" que resultarían más naturales en la variante del español de México. En el siguiente verso las pequeñas variaciones conciernen sólo a la disposición de las palabras. En cambio, se percibe una diferencia notable entre "Saciada", "Harta" y "Ahíta", al inicio del tercer verso, así como entre "mojada", "bañada" y "empapada" que cierran el último verso. En cuanto a las palabras de inicio del tercer verso, la elección de Colinas parece la más afortunada, pues, por un lado, la palabra

${ }^{20}$ [la perfecta transfiguración de un episodio geórgico en un símbolo de la condición universal de dolor inmanente tanto en los hombres como en la naturaleza]

${ }^{21}$ En los casos en que sea necesario señalar el significado preciso de alguna palabra en italiano o español, me basaré respectivamente en el Vocabolario Treccani (2020) y en el Diccionario de la Lengua Española (2020). 
"harta" utilizada por Del Re podría guardar una cierta carga negativa en su significado; por otro lado, el "ahíta" en la versión de Fernández remite, si no a un cultismo, sí a un registro lingüístico elevado.

En el cierre del cuarto verso, en cambio, tanto Colinas como Fernández se mantienen cerca del significado de bagnato (aunque la elección de "empapada" del segundo traductor se podría entender como "mojada en exceso", sentido no sugerido en el original). La elección de Fernández, además, podría verse en este caso como una suerte de compensación: "empapada", de registro coloquial, diluye en cierta medida el tono culto que "ahíta" sugiere, buscando, tal vez, la cualidad del lenguaje más llano e inmediato, característico de la poesía sabiana. La elección de Ana María del Re, por el contrario, da la idea de un falso cognado: en italiano bagnato alude únicamente a la propiedad del agua de "mojar" mientras que en español, en cambio, "bañado" remite, más bien, a una cuestión de limpieza. ${ }^{22}$ Aun así, la continuación del verso ("por la lluvia") sirve para volver al sentido del original.

En la segunda estrofa, Saba desarrolla el tema central y, para subrayar la importancia de estos versos, los dispone al centro del poema. El yo poético reconoce, en el monótono balido de la cabra, un sonido fraterno a su propio dolor y se siente movido a responder con el mismo sonido. Precisamente ese sonido, el del dolor invariable y eterno, se podía reconocer en el balido de aquella cabra solitaria. Al tratarse del tema cardinal del poema, esta segunda estrofa parece haber representado la de mayor dificultad para los traductores, o al menos eso sugieren las variaciones, de métrica e incluso de sentido, entre las tres versiones, como puede verse en la Tabla 2:

\section{Tabla 2}

Segunda estrofa de "La cabra"

\begin{tabular}{|c|c|c|}
\hline $\begin{array}{l}\text { Traducción } \\
\text { de Antonio Colinas }\end{array}$ & $\begin{array}{l}\text { Traducción } \\
\text { de Ana María del Re }\end{array}$ & $\begin{array}{l}\text { Traducción } \\
\text { de Guillermo Fernández }\end{array}$ \\
\hline $\begin{array}{l}\text { Aquel monótono balar se } \\
\text { identificaba } \\
\text { con mi dolor. Y yo le respondí, } \\
\text { primero } \\
\text { por bromear, después porque el } \\
\text { dolor es eterno, } \\
\text { y tiene una voz y no varía. } \\
\text { Era esta voz la que sentía } \\
\text { gemir en una cabra solitaria. }\end{array}$ & $\begin{array}{l}\text { Aquél monótono balido } \\
\text { acompañaba } \\
\text { mi dolor. Y respondí, primero } \\
\text { en broma, después porque el } \\
\text { dolor es eterno, } \\
\text { tiene una sola voz y no varía. } \\
\text { Escuchaba esa voz } \\
\text { gemir en una cabra solitaria. }\end{array}$ & $\begin{array}{l}\text { Su balido era fraterno, igual } \\
\text { a mi dolor. Primero le respondí } \\
\text { en broma, luego porque el dolor } \\
\text { es eterno. } \\
\text { Sólo tiene una voz y no cambia. } \\
\text { Esta voz escuchaba } \\
\text { gemir en una cabra solitaria. }\end{array}$ \\
\hline
\end{tabular}

Fuentes: Colinas (1977: 89), Saba (1989: 72) y Fernández (2006, 104)

${ }^{22}$ Según la primera acepción brindada por la RAE como una purificación. En mi opinión, el original más bien quiere subrayar la imagen de vulnerabilidad del animal que está solo, atado y, además, mojado por la lluvia. 
Hasta el primer punto, el poema señala la naturaleza del balido: monótono y fraterno al dolor del yo poético. Sólo en el caso de Colinas y Del Re se recuperan, aunque con matices distintos, estas dos cualidades. Colinas logra reproducir el significado, pero cambiando el sustantivo "balido" por el verbo "balar", así como el "era fraterno" por "se identificaba" (lo que al final hace que se pierda la rima del original entre el primero y el tercer verso). Del Re mantiene el "monótono balido"; sin embargo, en su lectura parece interpretar "fraterno" más como cercanía entre el balido y el dolor del yo poético y no tanto como un parecido o igualdad entre ellos (el caso de Colinas y Fernández). En la versión de Fernández, en cambio, se recupera sólo una de las cualidades de aquel sonido; es decir, que es fraterno, pero se elimina el hecho de que se trata de un sonido monótono, invariable. Esta omisión de Fernández podría parecer poco significativa, pues al final, la misma idea queda expresada versos adelante. Sin embargo, así disminuye la intensidad y la importancia - logradas precisamente por la repetición - que otorga Saba a la idea de que el dolor es siempre igual, invariable (tal como el balido) y que por ello identifica o hermana entre sí a todas las creaturas.

Es interesante también el contraste en la unidad de significado que explica por qué el yo lírico decide responder al monótono balido: en un primer momento, dice, lo hace por bromear, pero luego, porque el dolor es siempre el mismo, eterno. Colinas mantiene prácticamente invariable el sentido, a costa de alargar el verso, pues resulta muy complicado poder reproducir las dos sinalefas del original ("perché il" y "dolore è eterno"); en efecto, en ninguna de las tres versiones se mantiene la métrica de este fragmento. Por su parte, Del Re y Fernández optan por convertir el complemento de causa "per celia" (por broma, por bromear), en un complemento de modo "en broma". Llama la atención además la posición, al inicio del verso, del adverbio "primero" en la versión de Fernández. Al iniciar la oración con este adverbio ("Primero le respondí / en broma"), se esperaría una consecuente enumeración de acciones que siguiera a "respondí"; en cambio, aparece una explicación ("luego porque el dolor es eterno"). Esto cambia ligeramente el sentido del original, pues es cierto que hay una enumeración, pero ésta tiene que ver no con la acción de responder, sino con las dos causas que empujan al yo lírico a hacerlo: por bromear y porque el dolor es eterno.

En la última parte de la estrofa, salta a la vista una diferencia en la versión de Colinas: su interpretación de "sentire" como "sentir" ("Era esta voz la que sentía / gemir en una cabra solitaria") y no como el "escuchar", "oír" de las otras dos versiones. Según el Vocabolario Treccani, las dos acepciones están contenidas en el verbo (Instituto della Enciplopedia Italiana, s. f.), por lo que no sería un error la lectura de Colinas. Aun así, los elementos que completan el sentido del verbo apuntan más, quizá, al sentido del oído, pues por él es posible percibir el balido. Es claro que escuchar ese sonido podría generar también un sentimiento o emoción en el yo poético, pero esa reacción sería 
posterior al hecho más inmediato de oír. Cabe señalar además la focalización, enfatizada por Colinas, del elemento "Questa voce": también Saba subraya la importancia de este objeto directo al situarlo al inicio del verso (Questa voce sentiva gemere in una capra solitaria), pero el traductor español, además de mantener el elemento al inicio, decide transformarlo de objeto en sujeto de la oración (Era esta voz la que sentía / gemir en una cabra solitaria).

En la última estrofa, como ya lo anunciaba, el yo poético concluye diciendo que escucha el lamento de todos los pesares, de todas las vidas, en una cabra de rostro semita. De nuevo, encontramos el contraste entre las dos acepciones posibles del verbo "sentire". Ahora, como puede verse en la Tabla 3, sólo Colinas y Fernández conservan la interpretación que hicieran versos arriba: como sentimiento-sensación, el primero, y como percepción de sonido, el segundo. En cambio, Del Re modifica su elección anterior ("escuchaba") por "sentía":

\section{Tabla 3}

Tercera estrofa de "La cabra"

\begin{tabular}{lll}
\hline $\begin{array}{l}\text { Traducción } \\
\text { de Antonio Colinas }\end{array}$ & $\begin{array}{l}\text { Traducción } \\
\text { de Ana María del Re }\end{array}$ & $\begin{array}{l}\text { Traducción } \\
\text { de Guillermo Fernández }\end{array}$ \\
\hline $\begin{array}{l}\text { En una cabra de rostro semita } \\
\text { sentía quejarse cada mal ajeno, } \\
\text { cada ajena vida. }\end{array}$ & $\begin{array}{l}\text { En una cabra de rostro semita } \\
\text { sentía la marca de todos los males, } \\
\text { la queja de todas las vidas }\end{array}$ & $\begin{array}{l}\text { En una cabra de rostro semita } \\
\text { de cualquier otra vida. }\end{array}$ \\
\hline
\end{tabular}

Fuentes: Colinas (1977: 89), Saba (1989: 72) y Fernández (2006, 104)

Además, la traductora escribe "marca" ahí donde Colinas y Fernández, permaneciendo cerca del sentido de querelarsi, optan respectivamente por "quejarse" y "queja". La elección de Del Re remite a algo más físico: queda así eliminada la alusión al sonido del lamento de la cabra.

Por último, resta por señalar que todos los traductores cierran de manera distinta el poema. Es interesante, por ejemplo, que Colinas y Del Re traduzcan male por mal: es verdad que en español (como en italiano) la palabra "mal" contiene el sentido de pesar o pena; sin embargo, su uso con este significado resulta mucho más frecuente en italiano que en español. En efecto, la elección de Fernández en este verso resulta más directa.

La complejidad de estos últimos versos no se limita sólo a la palabra male: no es fácil reproducir el sentido de esta última parte con la misma inmediatez que en el original, conservando además las aliteraciones, el paralelismo y las anáforas que usa Saba al final de su poema: "sentivo querelarsi ogni altro male, / ogni altra vita". Como sucede en otros 
versos, también aquí Saba se sirve de las sinalefas para acentuar la unión entre las palabras y hacer más fluido el verso. A través de pocas palabras, el poeta sintetiza el tema fundamental del poema. Las tres versiones presentan diferentes soluciones: "sentía quejarse cada mal ajeno, / cada ajena vida" (Colinas); "sentía la marca de todos los males, / la queja de todas las vidas" (Del Re); "escuchaba la queja de otro dolor, / de cualquier otra vida" (Fernández). En el primer caso, el traductor busca recrear el efecto sonoro del original, aunque cambia el paralelismo por un quiasmo. En el plano del sentido, llama la atención, en cambio, su elección de "ajeno", que parece establecer cierta distancia (en lugar de la identificación de la que se habla a lo largo del poema) entre el yo lírico y "cada mal ajeno". Por otro lado, la versión de Del Re es más explicativa, ya que, a diferencia de las traducciones de Colinas y Fernández, ella incluye la palabra "marca" que no está en el original. Esta inclusión parece obligarla a escribir más adelante la palabra "queja" con la que recupera el sentido de querelarsi pero que borra la posibilidad de la aliteración del italiano. Finalmente, Fernández mantiene el endecasílabo del antepenúltimo y penúltimo verso, pero deja de lado la aliteración al preferir estructuras distintas, en lugar del paralelismo y la anáfora: "otro dolor" y "cualquier otra vida".

\section{Conclusiones}

Mi análisis no pretende determinar cuál de las tres versiones es la mejor; el objetivo ha sido, más bien, ver en qué medida la "poesía honesta" planteada por el poeta triestino se refleja en las traducciones al español. De la poética sabiana sería importante recordar, como apuntaba Portinari (1957), que no se restringe a un plano meramente estético, sino también moral y humano: en efecto, la primera demanda que Saba hace a los poetas es la honestidad; ninguna verdad puede nacer de una poesía artificiosa y efectista. Si el autor afirmaba categórico que los poetas debían hacer poesía honesta, siguiendo su poética y haciendo un paralelismo en el plano de la traducción, podríamos decir que el traductor que se proponga traducir la obra del poeta triestino debería hacer una traducción honesta. Esto implicaría que el traductor aprehendiera el tono (para decirlo con Levý) de la poesía sabiana: para ello sería fundamental conocer no sólo la obra poética, sino también las reflexiones del autor sobre su oficio, saber en qué condiciones llevó a cabo su labor poética, estar consciente de las circunstancias personales e históricas que pudieron influir en ella, etcétera.

Sería complicado saber hasta qué punto Colinas, Del Re y Fernández se adentraron en el universo sabiano; sin embargo, sí es posible observar qué rasgos característicos de esta poesía lograron reflejar en sus respectivas traducciones. La versión de Antonio Colinas parece haber logrado un equilibrio: si bien en algunas elecciones se aleja en 
cierta medida del sentido del original (por ejemplo, el uso de la palabra "ajeno" ahí donde Saba enfatiza justamente una identificación y no una extrañeza), en general su versión recupera las características esenciales del original tanto en la forma (en muchos casos mantiene la métrica, las rimas asonantes, las anáforas) como en lo referente al sentido fundamental del poema, que logra transmitir a través de un léxico llano tan típico en Saba. Por su parte, Ana María del Re reproduce elementos como la rima asonante y algunas repeticiones; sin embargo, en el plano léxico ciertas elecciones sugieren matices distintos al original. En este sentido, la versión de Del Re se aleja de la poética de Saba, pues, si bien el poeta rechazaba el lenguaje artificioso, en cambio le resultaba vital la búsqueda de la palabra precisa que, de verdad, reflejara lo que su ánimo le dictaba. Finalmente, Guillermo Fernández parece enfatizar el carácter prosístico típico de Saba al normalizar la sintaxis en algunos versos. Esta elección puede favorecer la fluidez, pero, en cambio, elimina ciertas rimas (particularmente en la primera estrofa). Quizá es justo por esta tendencia a prosificar que resulta aún más extraña la elección de "ahíta" que contrasta con el registro lingüístico general de la traducción. Esta inclusión pudo responder quizá a esos cultismos que el propio Saba, algunas veces, solía utilizar en sus poemas.

Como se puede observar, existen entre las tres versiones diferencias notables. Éstas, sin embargo, no deberían sorprendernos si consideramos que las tres traducciones surgen de la lectura e interpretación particular de cada traductor y que cada uno de ellos, a su vez, estaba inserto en un contexto determinado. Por esta razón sería injusto pretender determinar cuál de las tres versiones es la más afortunada, pues, por lo demás, no es posible saber ahora cuáles fueron los criterios de traducción que rigieron cada caso y mucho menos podríamos asegurar que entre dichos criterios estuviera el de reproducir la poética sabiana (que ha sido el punto de partida de mi análisis). En todo caso es innegable que tanto Colinas como Del Re y Fernández han logrado recuperar, en mayor o en menor medida, ciertas características esenciales de la poesía de Saba. Baste, pues, reconocer el valor ínsito de cada traducción al brindar al lector hispanohablante una oportunidad de adentrarse en la obra del gran Umberto Saba.

\section{Referencias bibliográficas}

Colinas, Antonio (Ed.). (1977). Poetas italianos contemporáneos (Antonio Colinas, Trad.). Madrid: Editora Nacional.

Fernández, Guillermo (Ed.). (2006). Veintidós poetas italianos. Para el bautismo de nuestros fragmentos (Guillermo Fernández, Trad.). México: UNAM. 
Gambarota, Paola. (2005). "Beyond Revealed Religions: Saba, the Creatures, and the Political Animal". MLN, 120(1), 137-160. http://doi.org/10.1353/mln.2005.0053

Istituto DELla EnCiclopedia ITAliana. (s. f.). Vocabolario Treccani (en línea). Recuperado el 02 de agosto de 2020 de http://www.treccani.it/vocabolario/

LevÝ, Jiri. (2011). The Art of Translation (Patrick Corness, Trad.). Amsterdam Philadelphia: John Benjamins.

Morante, Elsa. (1987). Pro o contro la bomba atomica e altri saggi. Milano: Adelphi.

Portinari, Folco. (1957). Umberto Saba. Milano: Murisia.

Real Academia Española. (2020). Diccionario de la Lengua Española (en línea). Recuperado el 09 de agosto de 2020 de https://www.rae.es/

SABA, Umberto. (1963). Storia e cronistoria del Canzoniere. Milano: Mondadori.

SABA, Umberto. (1989). El Cancionero: antología poética y cartas escogidas (Ana María del Re, Trad.). Caracas: Monte Ávila.

SABA, Umberto. (2001). Opere. Milano: Mondadori.

SABA, Umberto. (2014). Il canzoniere (1900-1945). Torino: Einaudi. 